\title{
Postoperative Analgesia after Combined Obturator Nerve and Adductor Canal Block in Total Knee Arthroplasty
}

\author{
Melike Şeyda Dağdelen*, Fatma Yeşim Abut, Veysel Erden and Seda Seven \\ Anesthesiology and Intensive Care Department, Istanbul Training and Research Hospital, Uludag \\ University, Turkey
}

*Corresponding author: Melike Şeyda Dağdelen, Anesthesiology and Intensive Care Department, Istanbul Training and Research Hospital, Uludag University, Faculty of Medicine Hospital, Bursa/Turkey, 16059, Tel: +905074292545; +902242953293, Fax: +90224295

\section{Abstract}

The purpose of this study was to evaluate adding an obturator nerve block to adductor canal block may reduce tramadol consumption (primary endpoint), improve pain relief, enhance early ambulation ability, and reduce side effects (secondary endpoints) after TKA compared with single adductor canal block. This study was carried out retrospectively in order to compare the effect of the single injection adductor nerve block, which was applied to the patients undergoing total knee arthroplasty (TKA) under spinal anesthesia by the Anesthesiology and Reanimation Clinic for the postoperative analgesia, and the single injection obturator block added to this on postoperative analgesia and participation in physiotherapy in relation to analgesia. The sample of this study was comprised of 60 patients who underwent knee arthroplasty under spinal anesthesia and peripheral nerve block for postoperative analgesia at the end of the operation by the Orthopedics and Traumatology clinic between January 2015 and January 2016. The patients were between 45-80 years old and in ASA I-II-III group. For the purpose of this study, patient records, pain follow-up forms and physiotherapy follow-up forms were retrospectively examined. The data related to patients' demographic characteristics, postoperative VAS scores, tramadol consumption, and tramadol related side effects, satisfaction levels and compliance with postoperative physical therapy were evaluated from printed data. The data of 30 out of the 60 patients to whom receiving only adductor canal block for analgesia were referred to as Group I and the data of the remaining 30 patients to whom receiving adductor canal block and obturator nerve block together for analgesia were defined as Group II were compared. The data of 3 patients in Group II were not included in the study because of the lack of records and a total of 57 patients were examined. No significant difference was identified between the groups in terms of age, gender, height, weight, ASA distribution and
\end{abstract}

tourniquet duration. The rate of diabetes mellitus (DM) in Group I was significantly higher than in Group II and the mean surgical time was significantly lower $(p=0.005, p=$ 0.030 ). Patients' VAS scores at $12^{\text {th }}$ hour were significantly higher in group I and no significant difference was found at $1^{\text {st }}, 4^{\text {th }}$ and $24^{\text {th }}$ hours. No significant difference was found between the groups in terms of tramadol consumption levels, nausea, vomiting, additional analgesic demand rates, satisfaction level distribution, maximum flexion to which the knee evaluated in physical therapy was able to reach and VAS score during that time, walking distance and chair test results $(p=0.506, p=0.390, p=0.656, p=0.217, p=$ $0.240, p=0.364, p=0.571, p=0.183, p=0.386)$. In conclusion, combination of obturator nerve block to adductor canal block did not provide a statistically significant contribution over single adductor canal block in terms of total tramadol consumptions, postoperative analgesia and early mobilization of the patients.

\section{Keywords}

Total knee arthroplasty, Postoperative analgesia, Adductor canal block, Obturator nerve block

\section{Introduction}

Despite the multimodal analgesia regimen, TKA operations are associated with serious postoperative pain. Therefore, approximately $40 \%$ of patients, due to the ongoing movement-related pain in the first and second postoperative days, restrict their mobilization, and this also increases the risk of complications associated with potential immobility [1]. Although systemic opioids or neuraxial techniques have been used for postoperative analgesia for a long time, as a result of the prevalence

Citation: Dağdelen MS, Abut FY, Erden V, Seven S (2019) Postoperative Analgesia after Combined Obturator Nerve and Adductor Canal Block in Total Knee Arthroplasty. Int J Anesthetic Anesthesiol 6:088. doi.org/10.23937/2377-4630/1410088

Accepted: April 15, 2019: Published: April 17, 2019

Copyright: (C) 2019 Dağdelen MS, et al. This is an open-access article distributed under the terms of the Creative Commons Attribution License, which permits unrestricted use, distribution, and reproduction in any medium, provided the original author and source are credited. 
of peripheral nerve block applications with the widespread use of ultrasonography (USG) and the increase of studies comparing these techniques, it has been observed that peripheral nerve blocks have superior analgesia level and fewer side effects $[2,3]$. Since knee joint innervation is multi-sourced, in conducted studies, many peripheral nerve blocks and their combination have been compared in terms of postoperative analgesia and the effect on mobilization. It has been observed that femoral nerve block is the application operating most extensively for TKA and that it provides significant analgesia in the first 24 hours. However, in recent years, the adductor canal block, which has been shown to be superior in terms of the fact that postoperative muscle strength allows the mobilization, has started to come forward. In studies comparing the adductor canal block with femoral blocks, it has been shown that the adductor canal block provides as effective analgesia level as the femoral block and makes less quadriceps weakness [4-6]. Considering the fact that the obturator nerve is a nerve that receives the sense of knee joint but its contribution in terms of postoperative analgesia is contradictory in the literature, it has been considered that this study will be able to clarify some uncertainty.

\section{Materials and Methods}

This study was carried out retrospectively after obtaining approval from the Clinical Research Ethics Committee of Istanbul Education and Research Hospital (Decision No: 83, on 23.09.2016). The sample of this study was comprised of 60 patients who underwent knee arthroplasty under spinal anesthesia and peripheral nerve block for postoperative analgesia at the end of the operation by the Orthopedics and Traumatology Clinic between January 2015 and January 2016. The patients were between $45-80$ years old and in ASA I-II-III group. For the purpose of this study, printed patient records; pain follow-up forms and physiotherapy follow-up forms were retrospectively examined. While the patients to whom only the adductor canal block was applied were called as Group I and it is consisted of 30 patients of the 60 patients. The patients to whom adductor canal block and obturator nerve block were applied together were called as Group II and it is consisted of the remaining 30 patients. The data of 3 patients in Group II were not included in the study because of the lack of records providing total tramadol consumption at Patient controlled analgesia (PCA), which is used for primary outcome and a total of 57 patients were examined.

In this study, the data of the patients who underwent general anesthesia, who had local anesthetics and/or allergy to drugs used in the study, who had ASA IV, who underwent revision total knee replacement, whose PCA device had malfunctioned due to any reason during the postoperative 24 hours and who had history of peripheral neuropathy or neuromuscular disease were excluded.
In our hospital, $12 \mathrm{mg}$ bupivacaine $+25 \mathrm{mcg}$ fentanyl is used for spinal anesthesia in TKA operations. Peripheral nerve blocks for postoperative analgesia are performed after preoperative patient approval, following the end of the Total Knee Arthroplasty, while patient monitoring continues in the operating room, and before taking down the surgical covers. Peripheral nerve blocks are applied by research assistants, experts (attending physicians) and lecturers trained in this field.

When applying the adductor canal block, under aseptic conditions, the linear ultrasound probe (My Lab Five brand ultrasound device, $10-18 \mathrm{MHz}$ ) is placed on the front face of the thigh of the patient, and on the approximate midpoint between the inguinal fold and medial condyle of the knee. Under the sartorius muscle, in the adductor canal, the arteria femoral is displayed. After displaying the vena femoral under the artery femoral and the nervus saphenous in its lateral, $10 \mathrm{~cm} 22 \mathrm{~g} 80 \mathrm{~mm}$ block needle (Pajunk, SonoPlex Stim cannula, USA) entry is made at the $1-2 \mathrm{~cm}$ lateral of the ultrasound probe by applying the in-plane technique. The needle is inserted under the sartorius muscle into the lateral of arteria femoral and narcissus saphenous, and after applying aspiration bupivacaine (bustesin $0.5 \%$, Vem Turkey) test at $10 \mathrm{ml} 0.5 \%$ concentration, it is injected into the adductor canal.

Obturator nerve block is performed with proximal interfacial technique described by Taha with USG [7]. After $10 \mathrm{ml}$ bupivacaine aspiration test is performed at $0.25 \%$ concentration on the apparent hyperechoic fascia between the pectineus, whose hyperechoic image adjacent to the deep lateral muscle fascicles of the ischial arm pectineus is detected, and the external obturator muscle, it is injected and it is observed that the local anesthetic is dispersed under the fascia of the pectineus muscle.

Whether or not peripheral nerve block is performed, PCA device is given to the patients and how to use it is described. After the collection of patients whose blocks have been completed, intravenous PCA devices are applied to them and then they are sent to the service. Intravenous PCA (CADD-legacy, model 6300 ambulatory infusion Pump) is routinely prepared with $100 \mathrm{ml}$ of $0.9 \%$ $\mathrm{NaCl}$ and $15 \mathrm{mg}$ tramadol bolus dose at a concentration of $4 \mathrm{mg} / \mathrm{ml}$ within a 20-minute lock-out time. When the patient has an additional analgesic requirement, $1 \mathrm{gr}$ IV paracetamol application is performed. All patients with PCA are visited by research assistants with analgesia follow up forms at $1^{\text {st }}, 4^{\text {th }}, 12^{\text {th }}$ and $24^{\text {th }}$ hours. VAS scores obtained by visual analog scale (VAS with $0-10 \mathrm{~cm}$ scale), amounts of tramadol consumption as milligram, nausea and vomiting that may be caused by Tramadol as side effects, and additional analgesic requirements are recorded routinely. Satisfaction level of the patients is assessed at the end of the $24^{\text {th }}$ hour with a 4-point Likert-type scale (very good, good, average and poor). 
Table 1: Demographic data.

\begin{tabular}{|c|c|c|c|c|}
\hline & & Group 1 & Group 2 & $P$ \\
\hline Gender (female) & & $27(\% 90)$ & $24(\% 82)$ & 0.478 \\
\hline Age (year) & & $67.7 \pm 7.8$ & $67.7 \pm 6.5$ & 0.998 \\
\hline Weight (kg) & & $77.9 \pm 11.4$ & $83.0 \pm 13.1$ & 0.207 \\
\hline Height (cm) & & $158.5 \pm 6.1$ & $159.0 \pm 6.9$ & 0.852 \\
\hline BMI $\left(\mathrm{kg} / \mathrm{m}^{2}\right)$ & & $31.0 \pm 4.3$ & $32.9 \pm 5.3$ & 0.338 \\
\hline \multirow[t]{3}{*}{ ASA } & I & $4(3.13)$ & $2(7.4)$ & 0.678 \\
\hline & II & $21(70)$ & $22(81.5)$ & \\
\hline & III & $5(16.7)$ & $3(11.1)$ & \\
\hline Diabetes mellitus & & 8 & 0 & 0.005 \\
\hline Surgical Duration (min) & & $94.0 \pm 18.0$ & $103.7 \pm 13.8$ & 0.030 \\
\hline tourniquet time (min) & & $79.0 \pm 17.8$ & $79.4 \pm 18.3$ & 0.974 \\
\hline
\end{tabular}

Values are given as $n(\%)$, mean \pm SD.

Table 2: 24-hour tramadol usage amounts and VAS values of the groups.

\begin{tabular}{|c|c|c|c|}
\hline & Group 1 & Group 2 & $P$ \\
\hline Tramadol (mg) & $227.0 \pm 108.0$ & $209.1 \pm 83.6$ & 0.506 \\
\hline VAS $1^{\text {st }}$ hour & $0.57 \pm 1.50$ & $0.41 \pm 1.47$ & 0.529 \\
\hline VAS $4^{\text {th }}$ hour & $5.33 \pm 1.47$ & $4.56 \pm 1.89$ & 0.104 \\
\hline VAS $12^{\text {th }}$ hour & $5.37 \pm 1.33$ & $4.33 \pm 1.59$ & 0.014 \\
\hline VAS $24^{\text {th }}$ hour & $2.63 \pm 1.19$ & $2.41 \pm 1.60$ & 0.180 \\
\hline
\end{tabular}

Values are given as mean \pm SD.

At the end of the $24^{\text {th }}$ hour, a physiotherapy program is initiated by the physical therapy team for the patients. In this program, the patient is first asked by the physiotherapist to bring his both hands to the maximum flexion through clamping them under the knee. VAS score for pain at that moment and passive flexion angle are recorded. Then, isometric extensor muscle exercises, foot shifting exercise, isometric exercises, sitto-stand and walking exercise is done. In sit-to-stand exercise, while the knees are 90 degrees on the flexion and suspended from the edge of the bed, the patient is asked to sit down and stand up as much as they can with taking support from the walker placed in front of them within 30 seconds. Each up and down is counted as a number. In total, it is recorded how many times the patients sit down and stand up. In walking exercise, first the patient is told how to use the walker, and then he is asked to walk the maximum possible distance within 3 minutes. At the end of the time, the distance is measured and recorded in meters. When evaluating the efficacy of physiotherapy, numerical values were compared using these records.

\section{Statistical Analysis}

For statistical analysis, SPSS 15.0 for Windows was used. Descriptive statistics were given as number and percentage for categorical variables, and as mean, standard deviation. The descriptive data (average, standard deviation, median, frequency, and ratio) and the quantitative data with non-normal distribution were analyzed using the Mann Whitney $U$ test. The Student's $t$ test was used for data with normal distribution. All statistical analyses were performed at a $95 \%$ confidence interval. A p-value $<0.05$ was considered significant.

\section{Results}

60 patients were included in the study. However, while the data were collected retrospectively, three patients in Group II were excluded from the study due to lack of data. No significant difference was identified between the groups in terms of age, gender, height, weight, ASA distribution and tourniquet duration. The rate of diabetes mellitus (DM) in Group I was significantly higher than in Group II and the mean surgical time was significantly lower (Table 1 ).

There was no statistically significant difference between groups in terms of tramadol consumption and postoperative Visual Analog Scale (VAS) values of the patients in the $1^{\text {st }}, 4^{\text {th }}, 12^{\text {th }}$ and $24^{\text {th }}$ hours are shown in Table 2.

Patients' VAS scores at $12^{\text {th }}$ hour were significantly higher in group I ( $p=0.014)$ and no significant difference was found at $1^{\text {st }}, 4^{\text {th }}$ and $24^{\text {th }}$ hours.

There was no statistically significant difference between groups in terms of tramadol related side effect rates and satisfaction levels ( $p>0.05$ ) (Table 3 and Table 4).

In the evaluation of the physiotherapy efficacy of Group I and II, any statistically significant difference was not identified. In addition, there was no significant difference in terms of VAS values in 45-degree passive flexion Table 5.

\section{Discussion}

Since knee joint innervation is multi-sourced, many combinations of peripheral nerve blocks have been investigated in terms of analgesia and efficacy. A randomized controlled study conducted by Macalou, 
Table 3: Tramadol related side effect and additional analgesic demand rates.

\begin{tabular}{|l|l|l|l|}
\hline & Group 1 & Group 2 & $\boldsymbol{P}$ \\
\hline Nausea & $10(33.3)$ & $12(44.4)$ & 0.390 \\
\hline Vomiting & $7(23.3)$ & $5(18.5)$ & 0.656 \\
\hline Additional analgesic demand & $8(28.6)$ & $4(14.8)$ & 0.217 \\
\hline
\end{tabular}

Values are given as $n(\%)$, mean $\pm S D$.

Table 4: Distribution of satisfaction level.

\begin{tabular}{|l|l|l|l|}
\hline Satisfaction & Group 1 & Group 2 & $\boldsymbol{P}$ \\
\hline $\mathbf{0}$ & $2(6.7)$ & $2(7.4)$ & 0.240 \\
\hline $\mathbf{1}$ & $11(36.7)$ & $7(25.9)$ & \\
\hline $\mathbf{2}$ & $8(26.7)$ & $14(51.9)$ & \\
\hline $\mathbf{3}$ & $9(30.0)$ & $4(14.8)$ & \\
\hline
\end{tabular}

Values are given as $\mathrm{n}(\%)$, mean $\pm \mathrm{SD}$; satisfaction level 0 : Poor, level 1: Fair, Level 2: Good, level 3: very Good.

Table 5: Postoperative physiotherapy results.

\begin{tabular}{|l|l|l|l|}
\hline & Group 1 & Group 2 & $\boldsymbol{P}$ \\
\hline Flexion (degree) & $39.2 \pm 14.0$ & $34.4 \pm 7.5$ & 0.364 \\
\hline VAS in Flexion & $5.7 \pm 1.2$ & $5.6 \pm 0.8$ & 0.571 \\
\hline Chair Test & $4.3 \pm 2.0$ & $4.8 \pm 2.3$ & 0.386 \\
\hline Walking Distance & $3.7 \pm 1.5$ & $4.3 \pm 1.7$ & 0.183 \\
\hline
\end{tabular}

Values are given as $n(\%)$, mean $\pm S D$.

et al. [8] showed that adding the obturator nerve block to the femoral 3-in-1 block after total knee arthroplasty increased analgesia. Similarly, McNamee, et al. [9] reported that the addition of the obturator nerve block in addition to the femoral and sciatic nerve block extended the additional analgesic duration and that they found a significant decrease in total morphine use. In these studies, the importance of obturator nerve in knee injury and therefore in postoperative analgesia was emphasized. However, in a randomized controlled study of Westergaad, et al. [10], 2 group of same-day arthroscopy patients who underwent only saphena nerve block and the obturator nerve block was added to this were compared for the purpose of postoperative analgesia and as a result, any difference in terms of the mean pain scores or total morphine consumption could not be found. Even, in a randomized, prospective and double-blind study comparing the functional status and analgesia between femoral, obturator and placebo groups after total knee arthroplasty, Kardash K. and colleagues showed that the obturator nerve block alone is inadequate [11].

In this study, $10 \mathrm{ml}$ dose was used for $A C B$, but this dose may not spread enough distally. Because, distal filling of the adductor canal will, in theory, ensure optimal analgesic effect of the ACB by blocking the four nerves traversing the canal. In a study done by $P$. Jaeger, et al. 5, 10, 15 and $20 \mathrm{ml}$ local anesthetic doses studied for investigating optimal dose that filling the distal adductor canal [12]. They found that distal filling of the adductor canal was optimal with $20 \mathrm{ml}$ dose. However, Takayuki, et al. showed with their study that the median effective volume of ropivacaine $0.5 \%$ was $10.4 \mathrm{~mL}$ for ultrasound-guided ACB [13]. If the dose used in this study was inadequate for distal spread, addition an obturator block to adductor canal block would be expected to increase analgesia. So, this may explain why $12^{\text {th }}$ VAS score lower in group 2 . And we think that because blocks performed single shot and no adrenalin added to prolong analgesic effect, this may explain statistically insignificance the subsequent VAS scores and total tramadol consumptions.

Our study has some limitations. Firstly, the data were gathered retrospectively and consecutively. The lack of randomization may lower the value of this study. However, there is no study in the literature that adding an obturator nerve block to adductor canal block may denser the obturator nerve block and improve analgesia after total knee arthroplasty. So, we cannot commad on the results in terms of accordance with the literature.

In conclusion, no difference was found between single adductor canal block and adding obturator nerve block to adductor canal block in the postoperative analgesia of patients undergoing total knee arthroplasty surgery with respect to opioid use and VAS and early mobilization of the patients.

In this retrospective study, no difference was found between single adductor canal block and adding obturator nerve block to adductor canal block in the postoperative analgesia of patients undergoing total knee arthroplasty surgery with respect to opioid use, VAS and early mobilization of the patients.

\section{References}

1. Williams-Russo $P$, Sharrock NE, Haas SB, Insall J, Windsor RE, et al. (1996) Randomized trial of epidural versus general anesthesia: Outcomes after primary total knee replacement. Clin Orthop 331: 199-208.

2. Wang H, Boctor B, Verner J (2002) The effect of singleinjection femoral nerve block on rehabilitation and length of hospital stay after total knee replacement. Reg Anesth Pain Med 27: 139-144.

3. Singelyn FJ, Deyaert M, Joris D, Pendeville E, Gouverneur JM (1998) Effects of intravenous patient-controlled analgesia with morphine, continuous epidural analgesia, and continuous three-in-one block on postoperative pain and knee rehabilitation after unilateral total knee arthroplasty. Anesth Analg 87: 88-92.

4. Jaeger $P$, Nielsen $Z J$, Henningsen $M H$, Hilsted $K L$, Mathiesen O, et al. (2013) Adductor canal block versus femoral nerve block and quadriceps strength: A randomized, double-blind, placebo-controlled, crossover study in healthy volunteers. Anesthesiology 118: 409-415.

5. Jenstrup MT, Jaeger P, Lund J, Fomsgaard JS, Bache S, et al. (2012) Effects of adductor-canal-blockade on pain and ambulation after total knee arthroplasty: A randomized study. Acta Anaesthesiol Scand 56: 357-364.

6. Kim DH, Lin Y, Goytizolo EA, Kahn RL, Maalouf DB, et al. (2014) Adductor canal block versus femoral nerve block 
for total knee arthroplasty: A prospective, randomized, controlled trial. Anesthesiology 120: 540-550.

7. Taha AM (2012) Brief reports: Ultrasound-guided obturator nerve block: A proximal interfascial technique. Anesth Analg 114: 236-239.

8. Macalou D, Trueck S, Meuret P, Heck M, Vial F, et al. (2004) Postoperative analgesia after total knee replacement: The effect of an obturator nerve block added to the femoral 3-in1 nerve block. Anesth Analg 99: 251-254.

9. McNamee DA, Parks L, Milligan KR (2002) Post-operative analgesia following total knee replacement: An evaluation of the addition of an obturator nerve block to combined femoral and sciatic nerve block. Acta Anaesthesiol Scand 46: 95-99.

10. Westergaard B, Jensen K, Lenz K, Bendtsen TF, Vazin M, et al. (2014) A randomised controlled trial of ultrasoundguided blockade of the saphenous nerve and the posterior branch of the obturator nerve for postoperative analgesia after day-case knee arthroscopy. Anaesthesia 69: 13371344.

11. Kardash K, Hickey D, Tessler MJ, Payne S, Zukor D, et al. (2007) Obturator versus femoral nerve block for analgesia after total knee arthroplasty. Anesth Analg 105: 853-858.

12. Jaeger $P$, Jenstrup MT, Lund J, Siersma $V$, Brøndum $V$, et al. (2015) Optimal volume of local anaesthetic for adductor canal block: Using the continual reassessment method to estimate ED95. Br J Anaesth 115: 920-926.

13. Yoshida T, Nakamoto T, Kamibayashi T (2017) Ultrasoundguided obturator nerve block: A focused review on anatomy and updated techniques. Biomed Res Int 2017: 7023750. 